\title{
Carbon monoxide activates large-conductance calcium-activated potassium channels of human cardiac fibroblasts through various mechanisms
}

\author{
Hyemi Bae ${ }^{1}$, Taeho Kim², and Inja Lim,* \\ ${ }^{1}$ Department of Physiology, College of Medicine, Chung-Ang University, Seoul 06974, ${ }^{2}$ Department of Internal Medicine, College of Medicine, Chung-Ang \\ University Hospital, Seoul 06973, Korea
}

\author{
ARTICLE INFO \\ Received November 17, 2020 \\ Revised February 8, 2021 \\ Accepted February 9, 2021

\section{*Correspondence \\ Inja Lim \\ E-mail: injalim@cau.ac.kr}

Key Words

Calcium-activated potassium channel

Carbon monoxide

Nitric oxide

Protein kinases

\begin{abstract}
Carbon monoxide (CO) is a cardioprotectant and potential cardiovascular therapeutic agent. Human cardiac fibroblasts (HCFs) are important determinants of myocardial structure and function. Large-conductance $\mathrm{Ca}^{2+}$-activated $\mathrm{K}^{+}(\mathrm{BK})$ channel is a potential therapeutic target for cardiovascular disease. We investigated whether CO modulates BK channels and the signaling pathways in HCFs using whole-cell mode patch-clamp recordings. CO-releasing molecules (CORMs; CORM-2 and CORM3 ) significantly increased the amplitudes of BK currents (IBK). The CO-induced stimulating effects on IBK were blocked by pre-treatment with specific nitric oxide synthase (NOS) blockers ( $\left(\mathrm{L}^{\mathrm{G}}\right.$-monomethyl arginine citrate and $\mathrm{L}-\mathrm{N}^{\mathrm{G}}$-nitroarginine methyl ester). 8-bromo-cyclic GMP increased IBK. KT5823 (inhibits PKG) or ODQ (inhibits soluble guanylate cyclase) blocked the CO-stimulating effect on IBK. Moreover, 8-bromo-cyclic AMP also increased IBK, and pre-treatment with KT5720 (inhibits PKA) or SQ22536 (inhibits adenylate cyclase) blocked the CO effect. Pre-treatment with Nethylmaleimide (a thiol-alkylating reagent) also blocked the $\mathrm{CO}$ effect on IBK, and DLdithiothreitol (a reducing agent) reversed the $\mathrm{CO}$ effect. These data suggest that $\mathrm{CO}$ activates IBK through NO via the NOS and through the PKG, PKA, and S-nitrosylation pathways.
\end{abstract}

\section{INTRODUCTION}

Carbon monoxide (CO), a biological gas, is known to have highly toxic and detrimental effects on the heart [1,2]. CO exposure can induce arrhythmia [3,4] and myocardial cell death, leading to cardiac fibrosis [5]. However, CO is now established as an important, biologically active signaling molecule generated through the heme oxygenase (HO)-catalyzed degradation of heme [6,7]. Atrial and ventricular cardiomyocytes constitutively express $\mathrm{HO}-2$, and various stress factors, including myocardial infarction [8], can increase the levels of inducible HO-1 [9]. Endogenously synthesized CO is being increasingly recognized as a potential therapeutic with important signaling functions in vari- ous diseases [10]. HO-derived CO protects the heart from transplant-associated ischemia-reperfusion injury [11]. The remarkable cardioprotective effects of HO-1 are best evidenced by its ability to regulate inflammatory processes, cellular signaling, and mitochondrial function, ultimately mitigating myocardial tissue injury and the progression of vascular proliferative disease [7].

Cardiac fibroblasts are the largest cell population in the permanent cellular constituents of the heart, which include cardiomyocytes, endothelial cells, and vascular smooth muscle cells [12]. Human cardiac fibroblasts (HCFs) have numerous functions, including the synthesis and deposition of extracellular matrix, and they play a relevant role in myocardial structuring and cell signaling in healthy and diseased myocardium [13]. HCFs have cell-cell

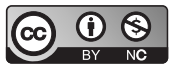

This is an Open Access article distributed under the terms of the Creative Commons Attribution Non-Commercial License, which permits unrestricted non-commercial use, distribution, and reproduction in any medium, provided the original work is properly cited. Copyright @ Korean J Physiol Pharmacol, pISSN 1226-4512, elSSN 2093-3827
Author contributions: H.B. performed all experiments. T.K. contributed to the study conception and analysis. H.B. and I.L. wrote the manuscript. I.L. supervised and coordinated the study. 
communication with cardiomyocytes and other cells [14], and the cardiomyocyte-cardiac fibroblast interactions are important in normal heart function and in the development of diseases such as cardiac arrhythmia and fibrosis [15].

It has been reported that cardiac fibroblasts can interact electrically with cardiomyocytes through gap junctions [16] and direct electrical coupling of these two types of cells has also been observed [16-18]. There is now increasing evidence that cardiac fibroblasts may play a direct role in modulating the electrophysiological substrate in healthy and diseased hearts [19]. In addition, cardiac injury results in significant electrophysiological changes that enhance fibroblast-myocyte interactions and could contribute to a greater incidence of arrhythmias observed in fibrotic hearts [20].

Although cardiac fibroblasts are non-excitable, they express multiple ion channels and the activity of ion channels in HCFs $[21,22]$ contributes to the functional activities of heart cells through the transfer of electrical signals between these two cell types [23]. However, the distribution and properties of their ion channels are quite distinct from those of cardiomyocytes [24].

The large-conductance $\mathrm{Ca}^{2+}$-activated $\mathrm{K}^{+}(\mathrm{BK})$ channel is the main $\mathrm{K}^{+}$channel in HCFs [22,25]. The BK channel contributes to the resting membrane potential of cardiac fibroblasts [26] and the electrical coupling of cardiomyocytes-fibroblasts [23]. BK channels are also mainly expressed in vascular smooth muscle cells [27] and in the inner mitochondrial membranes of the cardiomyocytes [28]. Activation of these channels in these locations results in cardioprotection against cardiac ischemia that induces arrhythmogenesis [29].

$\mathrm{CO}$ is rapidly emerging as an important cellular messenger, regulating a wide range of physiological processes. The investigation of ion channels as effectors of CO signaling is in its infancy, with regard to both the physiologic and the toxic activities of this gas. Various ion channels have recently been discovered to be effectors of CO signaling, and they play key roles in the mediation of beneficial effects of $\mathrm{CO}[30,31]$. $\mathrm{CO}$ also modulates various ion channels via diverse signaling pathways $[2,32,33]$.

Among them, $\mathrm{CO}$ activates BK channels in human endothelial cells directly as well as via a cGMP-dependent pathway [34] and in vascular smooth muscle cells directly but not mediated by a cGMP dependent pathway [35].

However, the effect of $\mathrm{CO}$ on the BK channel of HCFs and the underlying mechanism remains unclear. Therefore, we explored the effect of $\mathrm{CO}$, using CORMs, on BK current through the channels and their intracellular signaling pathways.

\section{METHODS}

\section{Cell culture and reagents}

Adult human cardiac ventricular fibroblasts were obtained from the ScienCell Research Laboratory (Cat \#6310; San Diego, CA, USA). The cells were cultured in Dulbecco's modified Eagle's medium (Welgene, Gyeongsan, Korea) with 10\% fetal bovine serum (Welgene) and a penicillin-streptomycin solution (100x; Welgene) in an incubator with a humidified atmosphere of 5\% $\mathrm{CO}_{2}$ and $95 \%$ air at $37^{\circ} \mathrm{C}$. Experiments were performed with cells from passage 4-7 (passage is the number of times the cells are processed with trypsin and transferred to another flask).

$\mathrm{CO}$ was applied to cells using the commercially available COdonors, carbon monoxide releasing molecules; CORM-2 (tricarbonyldichlororuthenium [II] dimer, $\left.\left[\mathrm{Ru}\left(\mathrm{CO}_{3}\right) \mathrm{Cl}_{2}\right]_{2}\right)$, CORM-3 (tricarbonylchloro-glycinate-ruthenium [II], $\left[\mathrm{Ru}(\mathrm{CO})_{3} \mathrm{Cl}\right.$-glycinate]), paxilline (a BK channel blocker), and all other chemicals were purchased from Sigma-Aldrich (St. Louis, MO, USA).

\section{Electrophysiological recordings}

Membrane ionic currents were recorded using the whole-cell patch-clamp technique, as described previously, using the Axopatch 200B Patch Clamp Amplifier (Axon Instruments, Union City, CA, USA).

The recording patch pipettes were prepared from filament-containing borosilicate tubes (TW150F-4; World Precision Instruments, Sarasota, FL, USA) using a 2-stage microelectrode puller (PC-10; Narishige, Tokyo, Japan) and were fire-polished using a microforge (MF-830; Narishige).

The pipettes for whole-cell currents exhibited a resistance of 2-3 $\mathrm{M} \Omega$ when filled with the internal pipette solution. The recorded membrane currents were filtered at $2 \mathrm{kHz}$ and digitized at $10 \mathrm{kHz}$. pCLAMP 9.0 software (Axon Instruments) was used for data acquisition and analysis of the whole-cell currents. All electrophysiological experiments were performed at room temperature.

For BK current recording, the cells were perfused with Tyrode solution containing $142 \mathrm{mM} \mathrm{NaCl}, 5 \mathrm{mM} \mathrm{KCl}, 1 \mathrm{mM} \mathrm{CaCl}_{2}, 1$ $\mathrm{mM} \mathrm{MgCl} 2,5 \mathrm{mM}$ glucose, and $5 \mathrm{mM}$ HEPES (pH-adjusted to 7.35 with $\mathrm{NaOH}$ ). The pipette solution contained $145 \mathrm{mM} \mathrm{KCl}$, $1.652 \mathrm{mM} \mathrm{CaCl}_{2}$ (pCa 6.0), $1.013 \mathrm{mM} \mathrm{MgCl}_{2}, 10 \mathrm{mM}$ HEPES, 2 mM EGTA, and 2 mM K-ATP (pH 7.3 with $\mathrm{KOH}$ ). All chemicals were purchased from Sigma-Aldrich. To record only IBK in the cells, we added 4-aminopyridine ( $1 \mathrm{mM})$ into the bath solution to exclude the influence of delayed rectifier $\mathrm{K}^{+}$channels, which are another source of the prominent $\mathrm{K}^{+}$currents in HCFs.

\section{Statistical analysis}

The results are presented as means \pm standard errors of the mean (SEM). Statistical analysis was performed using SPSS version 22.0 software (IBM Corp., Armonk, NY, USA). The paired Student's t-test was used to evaluate differences between the means of the 2 groups, whereas one-way analysis of variance was used for multiple groups. The p-values $<0.05$ were considered 
statistically significant.

\section{RESULTS}

\section{Effects of $\mathrm{CO}$ on large-conductance $\mathrm{Ca}^{2+}$-activated $\mathrm{K}^{+}$ currents of HCFs}

To determine the effect of $\mathrm{CO}$ on the BK channels in HCFs, we used whole-cell mode patch clamp recordings with a voltage protocol that consisted of depolarizing steps (from $-80 \mathrm{mV}$ to +50 $\mathrm{mV}$ ) in $10-\mathrm{mV}$ increments for 400 -ms with a holding potential of $-80 \mathrm{mV}$. The recorded macroscopic $\mathrm{K}^{+}$currents of HCFs exhibit behaviors typical of BK currents (IBK): activated at $10 \mathrm{mV}$, increased in voltage-dependent manner, and strongly oscillated in response to strong depolarization, well maintained throughout the test pulse without marked inactivation during depolarizing voltage increments (Fig. 1A). The average cell capacitance was

A

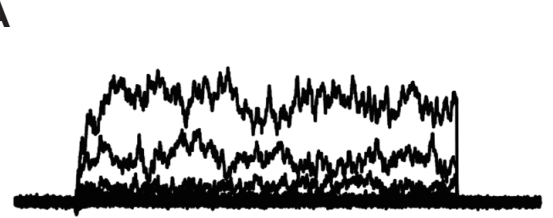

control

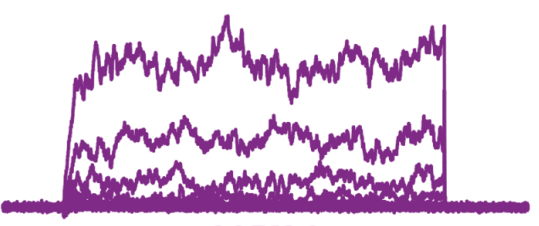

CORM-2

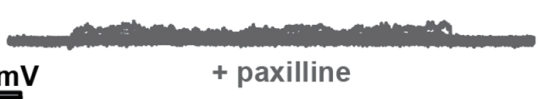

$500 \mathrm{pA}$ $100 \mathrm{~ms}$

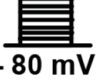

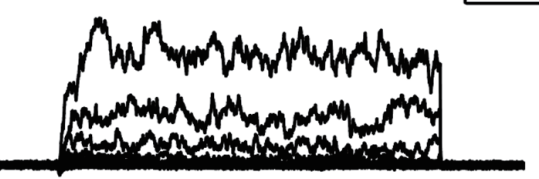

control

B
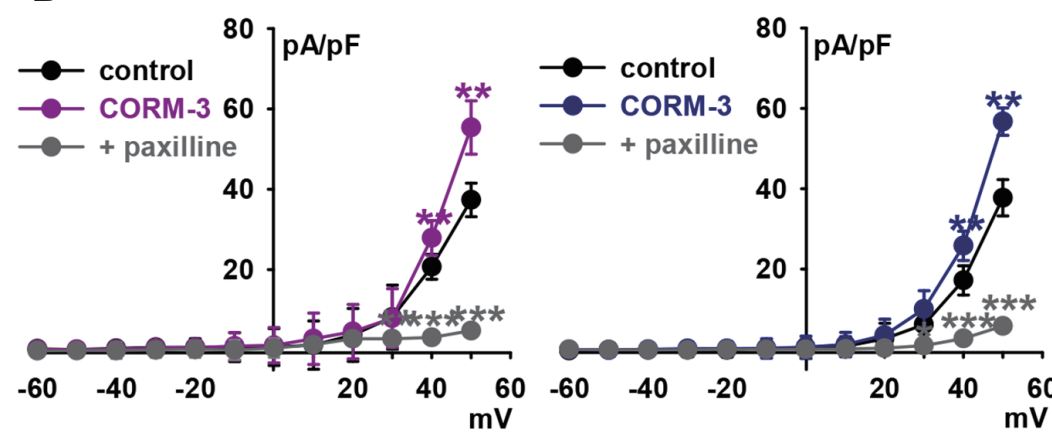

C

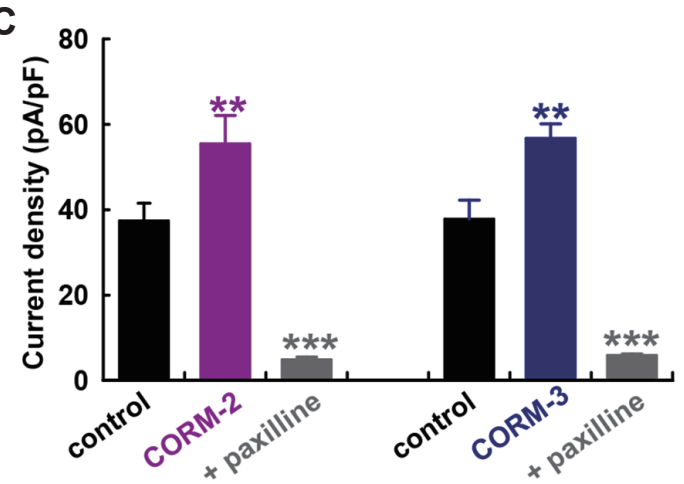

D
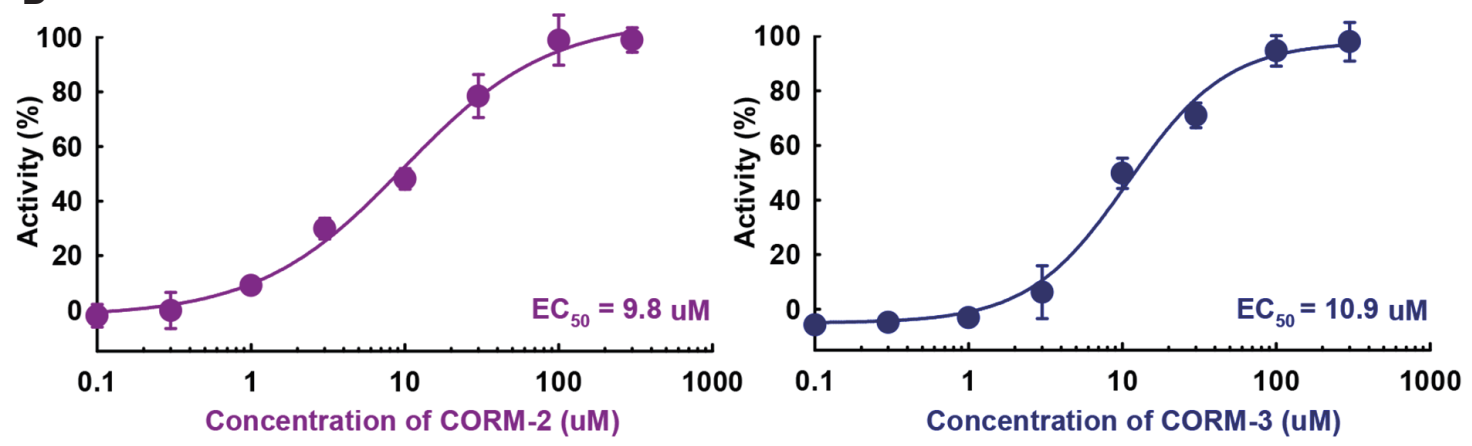

Fig. 1. Effects of carbon monoxide (CO) on large-conductance $\mathrm{Ca}^{2+}$-activated $\mathrm{K}^{+}$currents of $\mathrm{HCFs}$. (A) Original recordings of $\mathrm{K}^{+}$outward currents were obtained by repeated voltage step depolarization from -80 to $+50 \mathrm{mV}$ for $400 \mathrm{~ms}$ (holding potential, $-80 \mathrm{mV}$ ) before (control) and after the application of CO-releasing molecules (CORMs; CORM-2 or CORM-3, $10 \mu \mathrm{M}$, each) in whole-cell mode patch-clamp recordings. Paxilline (10 $\mu \mathrm{M})$ was added to confirm IBK. (B) Summarized current-voltage (I-V) curves for the effects of CO donors and paxilline show a strong outward rectification that characterizes IBK. Values are mean \pm SEM. ${ }^{* *} p<0.01$, ${ }^{* *} p<0.001$ compared to control $(n=10$, each). (C) Bar graphs showing the summary of the current density changes at $+50 \mathrm{mV}$ regarding the effects of CORM-2, CORM-3, and paxilline ( $n=10$, each). (D) Concentration-dependent activation curves of IBK by CORM-2 and CORM-3 are shown. The solid line shows the fit based on a standard dose-response relationship, which yielded an estimated half maximal effective concentration $\left(\mathrm{EC}_{50}\right.$ ) of $9.8 \mu \mathrm{M}$ for CORM-2 and $10.9 \mu \mathrm{M}$ for CORM-3. 
$23.44 \pm 0.46 \mathrm{pF}(\mathrm{n}=289)$. CO donors significantly increased the amplitude of the $\mathrm{K}^{+}$currents $(10 \mu \mathrm{M}$ CORM-2, $+48.2 \pm 16.0 \%$ of control; CORM- $3,+50.1 \pm 7.6 \%$ of control, at $+50 \mathrm{mV}, \mathrm{n}=10$, each, $\mathrm{p}<0.01$ ).

We then added $10 \mu \mathrm{M}$ paxilline, a specific BK channel blocker, to confirm $I B K$ and that the currents were blocked (CORM-2, $-87.0 \pm 1.6 \%$ of control; CORM- $3,-84.4 \pm 3.3 \%$ of control, at $+50 \mathrm{mV}, \mathrm{n}=10, \mathrm{p}<0.001)$. In addition, their current-voltage ( $I-$ $V)$ curves showed strong outward rectification, a characteristic of IBK (Fig. 1B). The bar graphs show the summary of the current density changes of these currents at $+50 \mathrm{mV}$ stimulation voltage (CORM-2, from $37.4 \pm 4.2$ to $55.4 \pm 6.7 \mathrm{pA} / \mathrm{pF}$; CORM-3, from $37.8 \pm 4.5$ to $56.7 \pm 3.4 \mathrm{pA} / \mathrm{pF}$; at $+50 \mathrm{mV}, \mathrm{n}=10, \mathrm{p}<0.01$, Fig. $1 \mathrm{C})$. Paxilline $(10 \mu \mathrm{M})$ significantly inhibited CO-induced $I B K$ activation (CORM-2, $4.9 \pm 0.7$; CORM-3, $5.9 \pm 0.3 \mathrm{pA} / \mathrm{pF}$, at $+50 \mathrm{mV}, \mathrm{n}$ $=10, p<0.001)$. Concentration-response curves of the $\mathrm{CO}$ donors showed steady-state currents normalized to the control data were fitted with the Hill equation (Fig. 1D), with the half maximal effective concentration $\left(\mathrm{EC}_{50}\right)$ value of $9.8 \mu \mathrm{M}$ for CORM-2 activation of IBK $\left(\mathrm{EC}_{50}\right.$ of CORM-3; $\left.10.9 \mu \mathrm{M}\right)$.

\section{Effects of NOS blockers on CO-induced IBK activation}

$\mathrm{CO}$ can regulate ion channels via the modulation of numerous signaling pathways. To investigate the signaling mechanism underlying the regulation of $\mathrm{BK}$ channels by $\mathrm{CO}$, we first explored the involvement of nitric oxide (NO) because $\mathrm{CO}$ is known to activate nitric oxide synthase (NOS) and soluble guanylate cyclase (sGC) [36], and crosstalk between $\mathrm{CO}$ and $\mathrm{NO}$ have also been reported [37]. Fig. 2 indicates that the ability of CORM-2 $(10 \mu \mathrm{M})$ to activate $I B K$ was significantly suppressed by pre-treatment with an NOS inhibitor, L- $\mathrm{N}^{\mathrm{G}}$-monomethyl arginine citrate (L-NMMA, $100 \mu \mathrm{M},-2.4 \pm 11.7 \%$ of control, Fig. $2 \mathrm{~A}$ and B). L-NMMA by itself did not affect the amplitude of IBK $(-4.1 \pm 10.4 \%$ of control, $\mathrm{n}=10$ ). Similarly, L-NMMA pre-treatment inhibited CORM3-induced $I B K$ activation $(10 \mu \mathrm{M},+3.1 \pm 11.9 \%$ of control, $\mathrm{n}=10)$.

$I B K$ was confirmed, which was significantly attenuated by 10 $\mu \mathrm{M}$ paxilline (CORM-2; $-87.9 \pm 4.1 \%$ of control, CORM-3; -87.3 $\pm 8.8 \%$ of control, $\mathrm{n}=12, \mathrm{p}<0.001)$. Pre-treatment of cells with another NOS blocker, $\mathrm{L}-\mathrm{N}^{\mathrm{G}}$-nitroarginine methyl ester (L-NAME, $100 \mu \mathrm{M})$, also attenuated the CO-induced IBK activation. After 20 min of L-NAME pre-treatment, CORM-2 $(-0.8 \pm 8.3 \%$ of control, $n=12$, Fig. 2 C and D) or CORM-3 ( $-0.2 \pm 9.1 \%$ of control, $n$ $=12$ ) could not increase $I B K$, and successive addition of paxilline
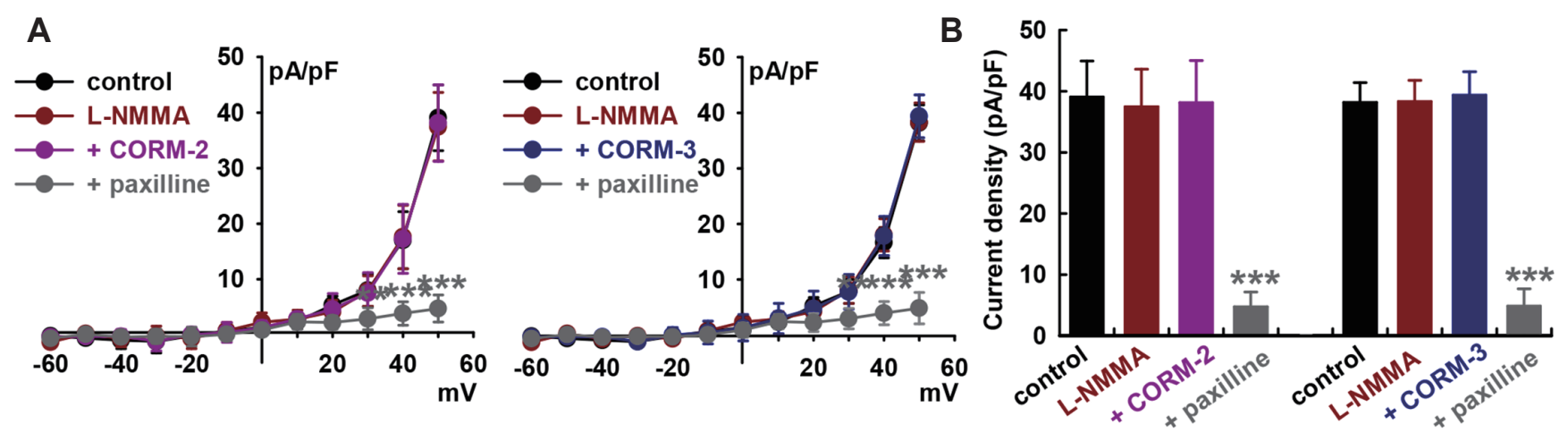

C
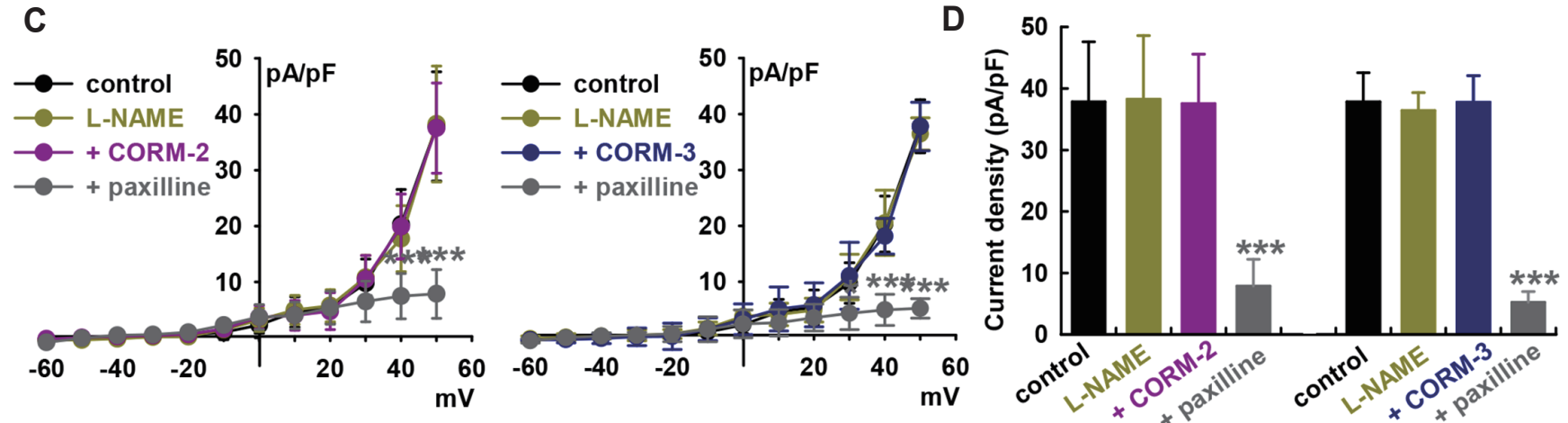

Fig. 2. Effect of nitric oxide synthase (NOS) blockers on CO-releasing molecule (CORM)-induced IBK activation. (A) Summarized current-voltage $(I-V)$ curves for the effects of CORM-2 or CORM-3 after L- $N^{G}$-monomethyl arginine citrate (L-NMMA, an NOS blocker, $\left.100 \mu M\right)$ pre-treatments. IBK was confirmed by $10 \mu \mathrm{M}$ paxilline. (B) Bar graphs show the summary of the current density changes regarding the effects of CORM-2 or CORM-3 (10 $\mu \mathrm{M}$, each) after L-NMMA $(100 \mu \mathrm{M})$ pre-treatments at $+50 \mathrm{mV}$. ${ }^{* *} \mathrm{p}<0.001$ paxilline $v$ s. control $(\mathrm{n}=10$, each). (C) Summarized $I-V$ curves for the effects of CORM-2 or CORM-3 after L-N $\mathrm{N}^{G}$-nitroarginine methyl ester (L-NAME, an NOS blocker, $100 \mu \mathrm{M}$ ) pre-treatments. (D) Bar graphs showing the summary of the current density changes regarding the effects of CORM- 2 or CORM-3 after L-NAME pre-treatments at $+50 \mathrm{mV}(\mathrm{n}=12$, each). 
after CO donors blocked the currents (CORM-2, $-79.2 \pm 4.5 \%$ of control; CORM-3, $-86.1 \pm 3.6 \%$ of control, $\mathrm{p}<0.001)$. These data suggest that $\mathrm{CO}$ could activate $I B K$ through NO formation via NOS.

\section{Effect of cGMP signaling pathway on CO-induced IBK activation in HCFs}

Binding of NO to the heme group of sGC leads to increased conversion of GTP to cGMP, which in turn activates PKG. The
cGMP signaling pathway are the main mechanisms for mediating the effects of NO on IBK in HCFs [25]. Therefore, we assessed the effects of cGMP on IBK of HCFs. Addition of 8-bromo-cGMP (a membrane-permeable cGMP analogue, $300 \mu \mathrm{M}$ ) increased the $I B K$ to $+55.1 \pm 9.2 \%$ of the control at $+50 \mathrm{mV}(\mathrm{p}<0.01, \mathrm{n}=8$, Fig. $3 \mathrm{~A}$ and $\mathrm{B})$.

When we pre-treated the cells with a PKG inhibitor, KT5823 $(1 \mu \mathrm{M})$, the CO donors failed to increase IBK (CORM-2, $+4.1 \pm$ $9.7 \%$ of the control at $+50 \mathrm{mV}, \mathrm{n}=8$; CORM-3, $+3.3 \pm 12.3 \%$ of control, $\mathrm{n}=8$, Fig. $3 \mathrm{C}$ and D). Similarly, pre-treatment of the cells
A

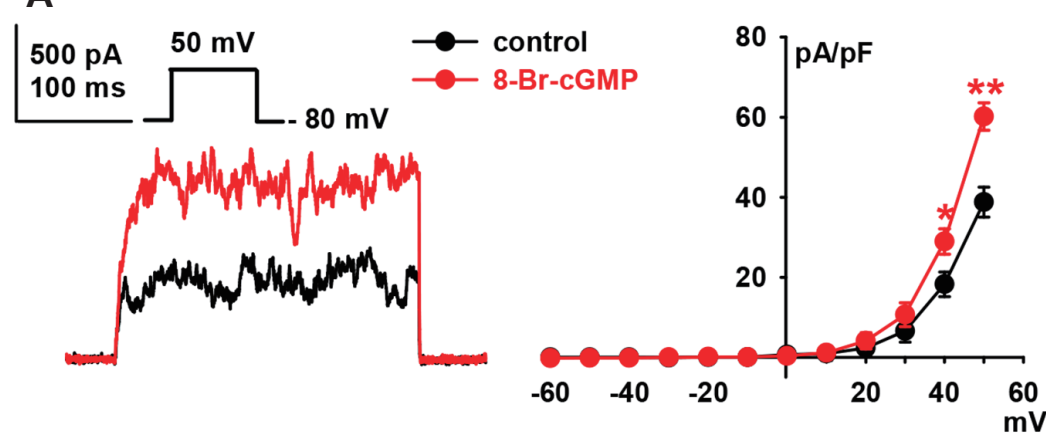

C

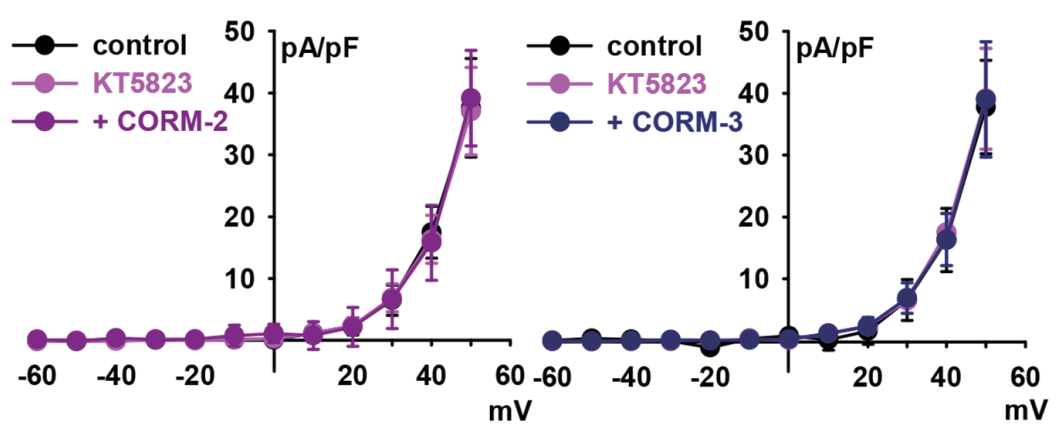

E

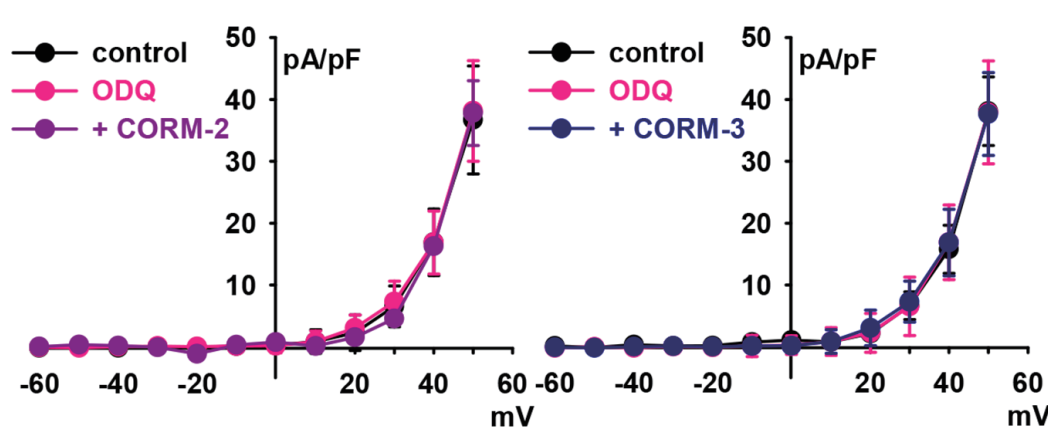

B

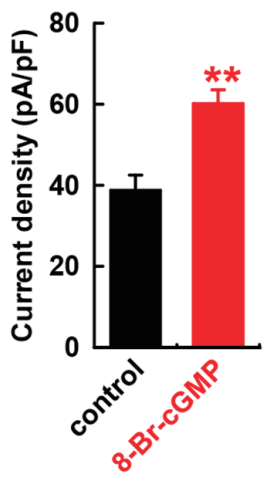

.

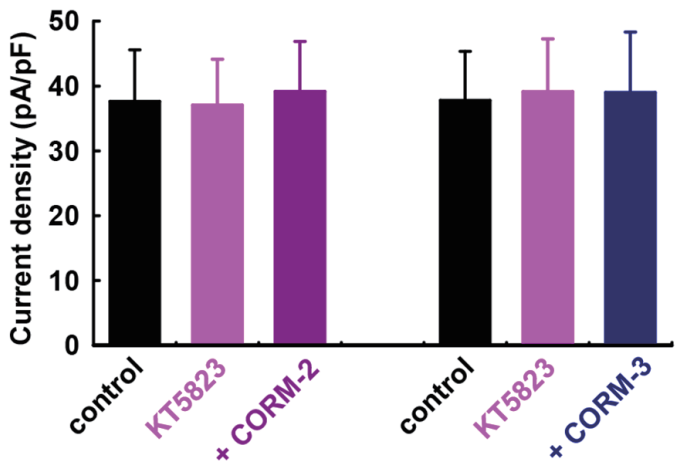

F

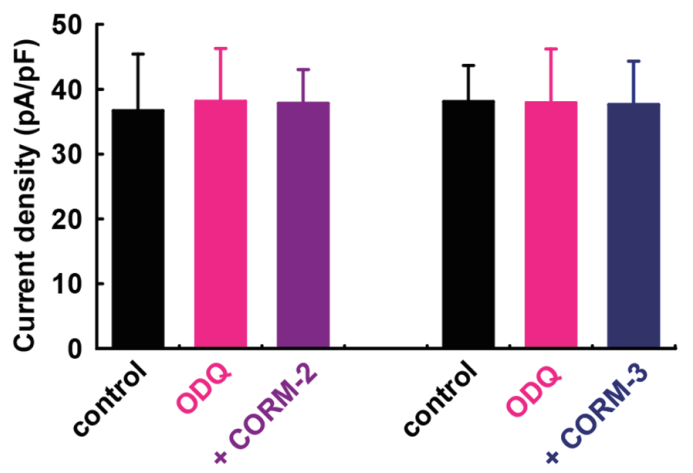

Fig. 3. Effect of CGMP signaling pathways on carbon monoxide (CO)-induced IBK activation in human cardiac fibroblasts (HCFs). (A) Representative currents and current-voltage $(I-V)$ curves show the summarized current density changes for the effect of $300 \mu \mathrm{M} 8-\mathrm{Br}-\mathrm{cGMP}$ on $I B K, \mathrm{n}=8$, ** $\mathrm{p}$ $<0.01$ vs. the control. (B) Bar graphs show the summary of the current density changes regarding the effect of $8-\mathrm{Br}-\mathrm{CGMP}(300 \mu \mathrm{M})$ at $+50 \mathrm{mV}$. Values are mean \pm SEM. (C) $I-V$ curves and (D) bar graphs also showing the summarized current density changes for the effect of pre-treatment with KT5823 (1 $\mu \mathrm{M}$, a PKG blocker) for 20 min for IBK activation induced by CO-releasing molecule (CORM)-2 (10 $\mu \mathrm{M}, \mathrm{n}=12)$ or CORM-3 (10 $\mu \mathrm{M}, \mathrm{n}=8)$. (E) $I-V$ curves and (F) bar graphs also showing the summarized current density changes for the effect of $10 \mu M$ CORM-2 $(n=12)$ or $10 \mu M$ CORM-3 ( $n=8)$ on IBK after pre-treatment with $1 \mu \mathrm{MODQ}$, a specific soluble guanylate cyclase (sGC) blocker. 
with $1 \mathrm{H}-[1,-2,-4]$ oxadiazolo-[4,-3-a] quinoxalin-1-one (ODQ; 10 $\mu \mathrm{M}$, a membrane-permeable sGC inhibitor) inhibited the COinduced activation of $I B K(C O R M-2,+3.1 \pm 6.0 \%$ of the control at $+50 \mathrm{mV}, \mathrm{n}=8$; CORM- $3,-1.2 \pm 12.1 \%$ of control, $\mathrm{n}=8$, Fig. $3 \mathrm{E}$ and F). KT5823 $(1 \mu \mathrm{M})$ or ODQ $(10 \mu \mathrm{M})$ alone did not increase the IBK of HCFs.

\section{Effect of cAMP signaling pathways on CO-induced IBK activation of HCFs}

To determine whether the cAMP signaling pathways are also involved in CO-induced $I B K$ activation, 8-bromo-cyclic AMP (8-Br-cAMP, a cyclic AMP analog, $300 \mu \mathrm{M}$ ) was added into the bath solution, which increased $I B K$ to $+52.7 \pm 14.3 \%$ of the control at $+50 \mathrm{mV}(\mathrm{p}<0.01, \mathrm{n}=8$, Fig. $4 \mathrm{~A}$ and B). Pre-treatment of the cells with KT5720 (1 $\mu \mathrm{M}$, a PKA blocker) for 20 min blocked COinduced IBK activation (CORM-2, $+0.2 \pm 11.9 \%$ of the control, at $+50 \mathrm{mV}, \mathrm{n}=8$; CORM- $3,-0.2 \pm 12.2 \%$ of the control, $\mathrm{n}=8$, Fig. 4C and D). Pre-treatment with SQ22536 $(1 \mu \mathrm{M}$, an adenylate cyclase blocker) also inhibited CO-induced IBK activation (CORM2 , control, $+0.4 \pm 7.0 \%$ of the control, $n=8$; CORM- $3,+1.7 \pm 7.4 \%$ of the control, $n=8$, Fig. 4E and F). KT5720 $(1 \mu \mathrm{M})$ or SQ22536 (1
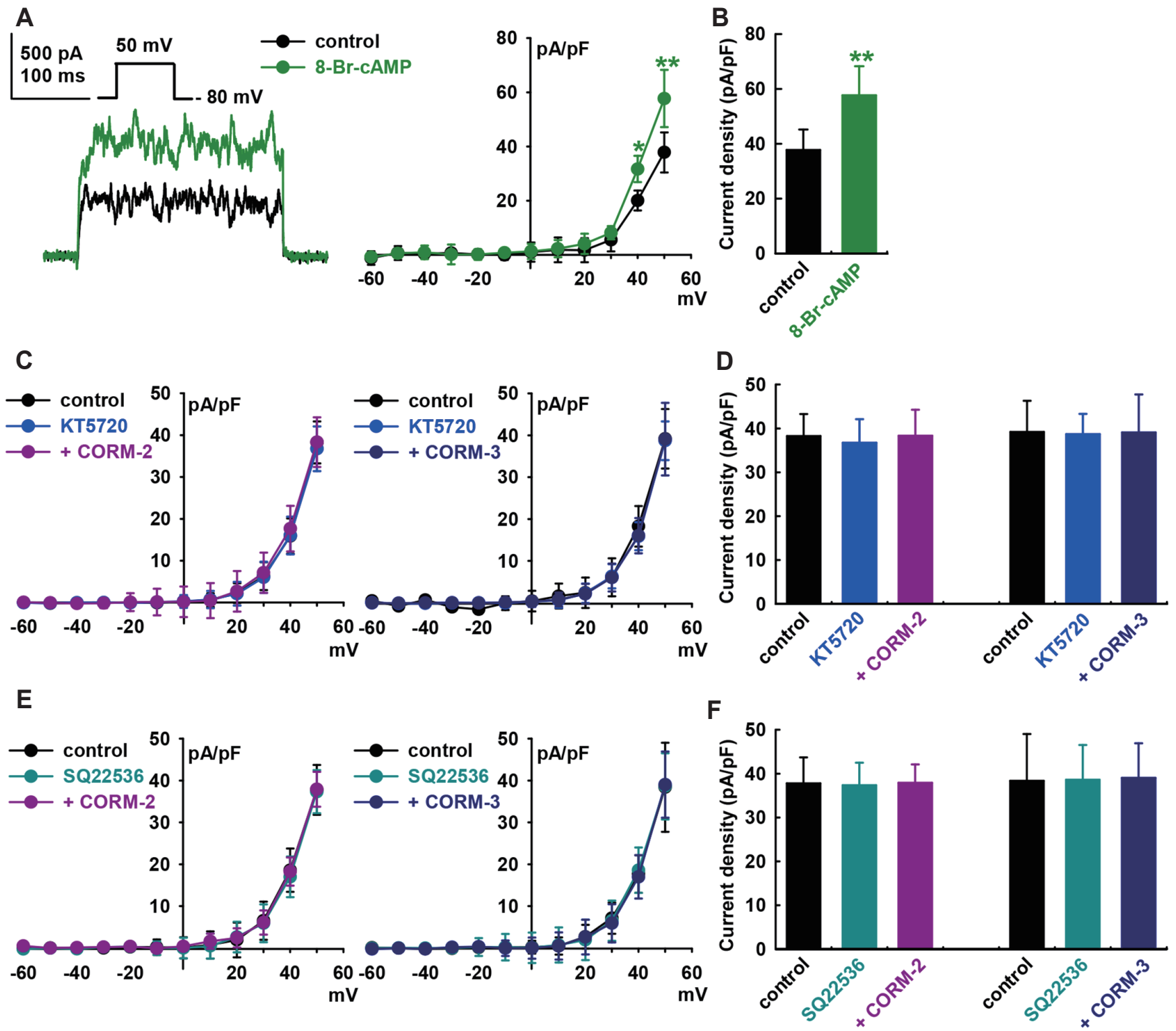

Fig. 4. Effect of the CAMP signaling pathway on the carbon monoxide (CO)-induced IBK activation of human cardiac fibroblasts (HCFs). (A) Representative currents and current-voltage $(I-V)$ curves showing the summary of the current density changes regarding the effect of 8-Br-cAMP (300 $\mu \mathrm{M}$ ) on IBK ( $\mathrm{n}=8,{ }^{*} \mathrm{p}<0.05,{ }^{* *} \mathrm{p}<0.01$ vs. the control). (B) Bar graphs at $+50 \mathrm{mV}$ show the summarized current density changes by $8-\mathrm{Br}-\mathrm{CAMP}$ (300 $\mu \mathrm{M}, \mathrm{n}=8$ ) on the IBK. (C) $I-V$ curves and (D) bar graphs show the summarized current density changes for the effect of $10 \mu \mathrm{M}$ CO-releasing molecule (CORM)-2 $(n=8)$ or $10 \mu$ M CORM-3 $(n=8)$ on IBK after pre-treatment with KT5720 $(1 \mu M)$ for 20 min. (E) I-V curves and (F) bar graphs show the summarized current density changes for the effect of $10 \mu \mathrm{M}$ CORM-2 $(n=8)$ or $10 \mu \mathrm{M} \mathrm{CORM}-3(n=8)$ on IBK after pre-treatment with SQ22536 $(1 \mu \mathrm{M})$ for $20 \mathrm{~min}$. 
$\mu \mathrm{M})$ alone did not increase the IBK of HCFs.

\section{Influence of S-nitrosylation on CO-induced IBK activation}

To establish $S$-nitrosylation as a mechanism for CO-mediated activation of $I B K$, we pre-treated cells with a thiol-alkylating reagent, N-ethylmaleimide (0.5 mM, NEM), for $20 \mathrm{~min}$ and then applied the CO donors. In the presence of NEM, CO donors could not increase $I B K$ compared to the value in the presence of NEM alone (CORM-2, $-3.0 \pm 7.6 \%$ of the control, $n=6$; CORM$3,-1.2 \pm 5.9 \%$ of the control, $n=6$, Fig. $5 \mathrm{~A}$ and $\mathrm{B}$ ).

When DL-dithiothreitol (DTT, a reducing agent; $5 \mathrm{mM}$ ) was applied after IBK had been increased by CORM-2, it reversed the effect of CORM-2 on IBK (CORM-2, $+47.0 \pm 9.8 \%$ of the control, $\mathrm{n}=6,{ }^{* *} \mathrm{p}<0.01$ vs. control; DTT, $+11.0 \pm 7.8 \%$ of the control, $\mathrm{n}=6$, ${ }^{*} \mathrm{p}<0.05$ vs. CORM-2, Fig. 5C and D). In case of CORM-3, DTT also reversed the CORM-3-induced increase of IBK (CORM-3, $+57.9 \pm 3.9 \%$ of the control, $\mathrm{n}=6,{ }^{*} \mathrm{p}<0.01$ vs. control; DTT, +4.5 $\pm 9.9 \%$ of the control, $n=6,{ }^{*} \mathrm{p}<0.05$ vs. CORM-3). These findings further suggest that $S$-nitrosylation is one of the mechanisms behind CO-induced IBK activation in HCFs, and a thiol residue could be the ultimate target of $\mathrm{CO}$.

\section{DISCUSSION}

\section{$\mathrm{CO}$ activation of the BK currents of HCF}

In our results, $\mathrm{CO}$ produced a concentration-dependent activation of IBK (Fig. 1). This result is consistent with the results for BK channels in human endothelial cells [34], in vascular smooth muscle cells [35], and in the mitochondrial BK channels of cardiomyocytes [38].

Previously, we have shown that the presence of the BK channel in the plasma membrane of HCFs by RT-PCR and Western blotting [21] and here confirmed its presence functionally by applying an electrophysiological method with paxilline, a specific BK channel blocker that exclusively uses a closed-channel block mechanism [39]. BK channels of the plasma membrane share multiple biophysical similarities with the BK channels in the inner mitochondrial membrane [38]. The protective effects of mitochondrial BK channel activation against ischemia were demonstrated by using BK channel openers [40] and BK channel knockout mice [41]. Therefore, considering the electrical coupling of cardiomyocytes-fibroblasts [23], BK channels of the plasma membrane of HCF could also be a potential target for cardiovascular diseases [42], and CO as a BK channel activator could be employed as a cardioprotectant.
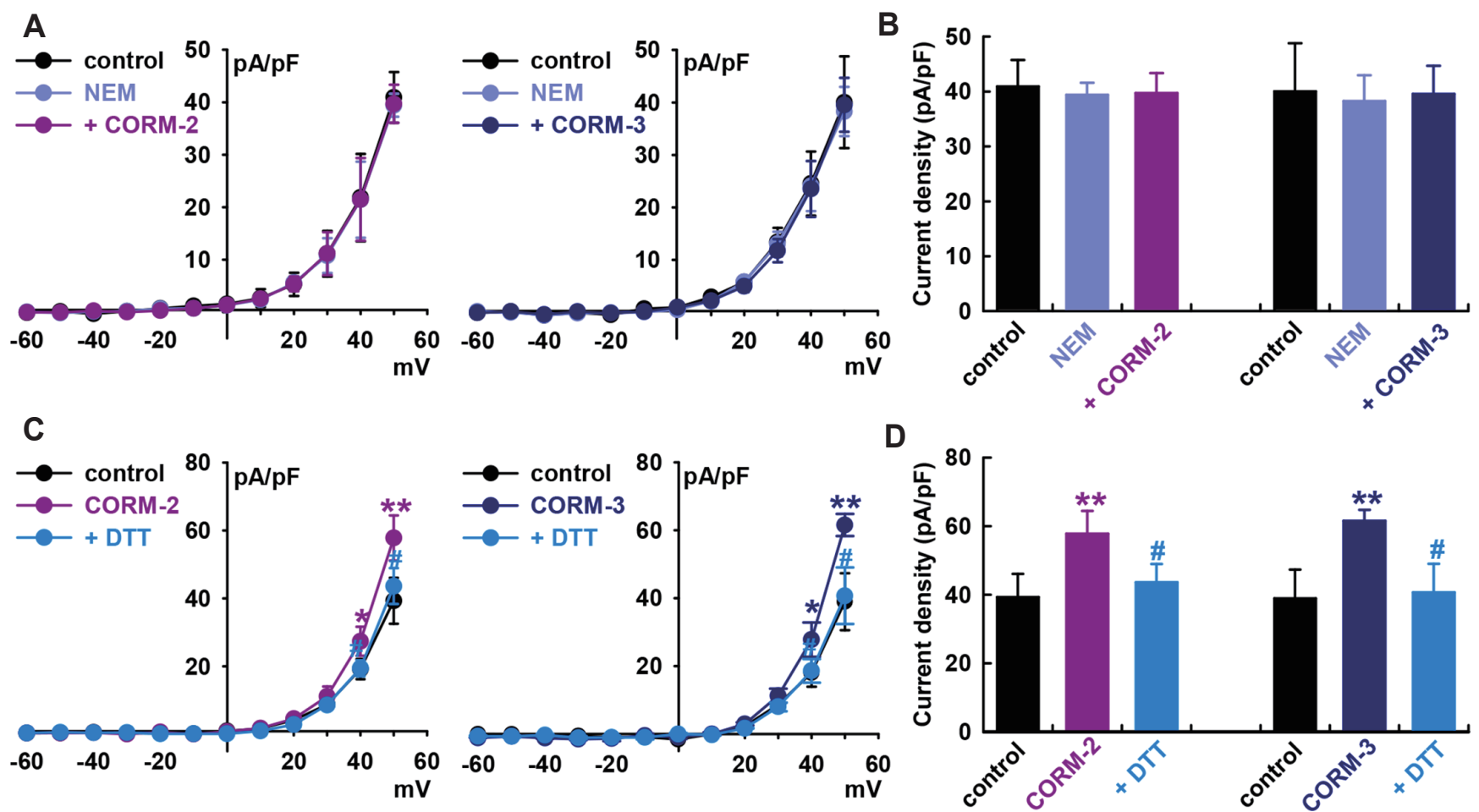

Fig. 5. Effect of S-nitrosylation on carbon monoxide (CO)-induced IBK activation. (A) Current-voltage (I-V) curves from -60 to $+50 \mathrm{mV}$ and (B) bar graphs at $+50 \mathrm{mV}$ showing the summarized current density changes by CO-releasing molecule (CORM)-2 (10 $\mu \mathrm{M}, \mathrm{n}=6)$ or CORM-3 (10 $\mu \mathrm{M}, \mathrm{n}=6)$ on IBK after pre-treatment with $\mathrm{N}$-ethylmaleimide (NEM, a thiol-alkylating reagent, $0.5 \mathrm{mM}$ ). (C) $I-V$ curves and (D) bar graphs showing the summarized current density changes for the effect of CORM-2 $(n=6)$ or CORM-3 $(n=6)$ on IBK after pre-treatment with DL-dithiothreitol (DTT, a reducing agent; 5 $m M) .{ }^{*} p<0.05,{ }^{* *} p<0.01$ vs. the control, ${ }^{*} p<0.05$ vs. CORMs. 
For studies on CO signaling, cells and channels have been exposed to $\mathrm{CO}$ by the application of $\mathrm{CO}$-releasing molecules (CORMs) that are a group of compounds capable of carrying and liberating controlled quantities of $\mathrm{CO}$ into cellular systems [6]. CORMs are fully water soluble, allow for intravenous administration, and rapidly liberate $\mathrm{CO}$ and hence have been used as $\mathrm{CO}$ donors to overcome the limitations of using $\mathrm{CO}$ gas [43]. In addition, CORMs are valuable experimental tools and potential therapeutic agents [6]. They have the potential for vasodilatory, antiischemic, and anti-inflammatory effects $[44,45]$ and they could protect adult cardiomyocytes against hypoxia-reoxygenation [46]. Therefore, the use of CORMs to investigate the signaling properties of $\mathrm{CO}$ has provided many new applications and treatments as pharmacologic approaches to cardiovascular diseases [6].

However, some of their actions can occur independently of $\mathrm{CO}$ release [47] or they show different activities. CO has positive inotropic activity in the perfused rat heart by CORM-3 but not by CORM-2 [48]. Judicial use of appropriate control compounds, as well as a comparison of their effects with those of $\mathrm{CO}$ diluted directly into a solution, should be performed wherever experimentally possible. When we tested two frequently used two types of CORMs of different structures to confirm the CO effect on BK channels, CORM-2 and CORM-3 showed similar activating effects on IBK of HCFs; the $\mathrm{EC}_{50}$ value was $9.8 \mu \mathrm{M}$ for CORM-2 and $10.9 \mu \mathrm{M}$ for CORM-3.

\section{CO activation of BK currents of HCF through NO}

To investigate the mechanism of the regulation of $\mathrm{BK}$ channels by $\mathrm{CO}$, we first explored the involvement of $\mathrm{NO}$ because $\mathrm{CO}$ and $\mathrm{NO}$ are two endogenously produced gases that can act as second messenger molecules and it is becoming increasingly clear that these two gases do not always work independently, but rather can modulate each other's activity [37]. CO induces NO release [49] and $\mathrm{NO}$ increases the expression of HO-1 in endothelial cells [50] or vascular smooth muscle cells [51].

Our results also demonstrated that the activation of IBK by CO in HCFs was abolished by treatment with L-NMMA or L-NAME, NOS blockers (Fig. 2). These results are consistent with the finding that $\mathrm{CO}$ activates L-type calcium channels in HEK cells and in human intestinal smooth muscle cells [36], and it stimulates BK channels in human endothelial cells [34] through NOS activation. The NO donor also stimulates IBK of HCFs [25].

\section{Signaling pathways involved in the effects of $\mathrm{CO}$ on BK currents of HCFs}

$\mathrm{CO}$ is an endogenous modulator of the NO-cyclic GMP signaling system [52] and activates L-type calcium channels through NO- and cGMP dependent pathways [36]. Both CO [49] and $\mathrm{NO}$ [25] activate ion channels via the activation of sGC, which generates cGMP.
Our results demonstrated that 8-bromo-cGMP increased IBK (Fig. 3) and the CO-induced IBK stimulation effect in HCFs was blocked by the presence of a sGC blocker (ODQ) or a PKG blocker (KT5823). These results suggest that the stimulatory effects of $\mathrm{CO}$ are dependent on the sGC/cGMP/PKG signaling pathway. These results are consistent with that of a previous study on the effect of $\mathrm{CO}$ in human endothelial cells [34] and NO in HCFs [25].

$\mathrm{CO}$ is a weak stimulator of sGC compared with NO because $\mathrm{CO}$ binds to the sGC heme group with a lower affinity and can only weakly increase cyclic activity. The binding only results in a four- to six-fold activation of the enzyme. Unlike CO, NO increases the sGC activity 100-400-fold [37]. In previous reports, $\mathrm{CO}$ amplifies NO-induced cGMP levels seen with either CO or NO alone [53] and potentiates the elevation of NO-mediated cGMP [52]. Therefore, it seems that CO can function as a partial agonist to facilitate NO-mediated activation of sGC.

NO can exert many of its effects through cGMP-independent mechanisms: the c-AMP dependent pathways and $S$-nitrosylation. NO modulates BK channels through cAMP-dependent pathways in HCFs [25] and in rat cardiac fibroblasts [54]. NO also blocks Kv1.5 channels by $S$-nitrosylation [55]. Our results also demonstrated that the stimulating effects of $\mathrm{CO}$ of HCFs were mediated by cGMP-independent mechanisms; cAMP-dependent pathways and $S$-nitrosylation.

In our study, pre-treatment with a PKA blocker (KT5720) or an adenylate cyclase blocker (SQ22536) inhibited the effect of CO on the IBK in HCFs and cell membrane permeable cAMP, 8-bromocAMP treatment increased IBK (Fig. 4), which means that the cAMP-dependent pathway is also involved in the stimulating effect of $\mathrm{CO}$ on $I B K$ in HCFs. These results are similar to the finding that NO increases IBK through PKG- and PKA-related pathways in HCFs [25] and cAMP-dependent vasodilators crossactivate the cGMP-dependent protein kinase pathway to stimulate BK channels in coronary artery smooth muscle cells [56].

We also found that CO could activate IBK in HCFs through $S$ nitrosylation, since a thiol-alkylating reagent, NEM, prevented CO stimulation effects on $I B K$ and a reducing agent, DTT reversed the effect of CORMs on IBK (Fig. 5). This is the first report that an $S$-nitrosylation mechanism is involved in $\mathrm{CO}$ effects on $I B K$ in a cardiac system and that a thiol residue could be the ultimate target of CO.

$S$-nitrosylation has emerged as an important and ubiquitous post-translational modification system, participating in cellular signaling (reviewed in Gonzalez et al.) [57]. Several reports exist on the effect of $\mathrm{NO}$ mediated through $S$-nitrosylation being implicated in all major functions of NO in the cardiovascular system [57-59]. Since $S$-nitrosylation signaling is involved in multiple physiological processes, it is expected that altered $S$-nitrosylation of specific ion channels may be relevant in some pathologic states, arrhythmia and heart failure.

Cardiac ion channels involved in excitation-contraction coupling are potentially regulated by $S$-nitrosylation [57]. In cardiac 
myocytes, $S$-nitrosylation is coupled to NOS activity for Nav1.5 channel activation [60]. NO inhibits L-type calcium channels by $S$-nitrosylation [61] and the $\alpha 1$-subunit of L-type calcium channels is constitutively $S$-nitrosylated in the mouse heart [62]. $S$-nitrosylation increases the slowly activating component of delayed rectifier $\mathrm{K}^{+}$currents in a manner dependent on NOS $[63,64]$ and Kv4.3 channels, which generates a transient outward $\mathrm{K}^{+}$current [65].

Although BK channels are not expressed in the plasma membrane of cardiomyocytes, recent works showed that BK channels might localize at the sinoatrial node in the heart and contribute to the regulation of sinoatrial node cell automaticity. Application of paxilline significantly reduced the action potential firing of sinoatrial node cells and lengthened the diastolic depolarization phase of the action potential [66].

Considering fibroblast-myocyte electrotonic coupling [67], BK channels of HCFs and the $\mathrm{CO}$ effects on this the channel may lead to the discovery of novel therapeutic targets and the development of agents for improving outcomes of heart diseases.

In summary, the present study showed for the first time that $\mathrm{CO}$ stimulates BK channels of HCFs, which involves the activation of $\mathrm{NO}$ by NOS and the sGC/cGMP/PKG, adenylate cyclase/ cAMP/PKA, and $S$-nitrosylation pathways.

\section{ACKNOWLEDGEMENTS}

This research was supported by the Basic Science Research Program through the National Research Foundation of Korea (NRF) funded by the Ministry of Education (NRF-2018R1D1A1B07048607).

\section{CONFLICTS OF INTEREST}

The authors declare no conflicts of interest.

\section{REFERENCES}

1. Marchewka J, Gawlik I, Dębski G, Popiołek L, Marchewka W, Hydzik P. Cardiological aspects of carbon monoxide poisoning. Folia Med Cracov. 2017;57:75-85.

2. Peers C, Steele DS. Carbon monoxide: a vital signalling molecule and potent toxin in the myocardium. J Mol Cell Cardiol. 2012;52:359-365.

3. André L, Gouzi F, Thireau J, Meyer G, Boissiere J, Delage M, Abdellaoui A, Feillet-Coudray C, Fouret G, Cristol JP, Lacampagne A, Obert P, Reboul C, Fauconnier J, Hayot M, Richard S, Cazorla O. Carbon monoxide exposure enhances arrhythmia after cardiac stress: involvement of oxidative stress. Basic Res Cardiol. 2011;106:12351246.

4. Dallas ML, Yang Z, Boyle JP, Boycott HE, Scragg JL, Milligan CJ,
Elies J, Duke A, Thireau J, Reboul C, Richard S, Bernus O, Steele DS, Peers C. Carbon monoxide induces cardiac arrhythmia via induction of the late $\mathrm{Na}^{+}$current. Am J Respir Crit Care Med. 2012;186:648-656.

5. Gandini C, Castoldi AF, Candura SM, Locatelli C, Butera R, Priori S, Manzo L. Carbon monoxide cardiotoxicity. J Toxicol Clin Toxicol. 2001;39:35-44.

6. Motterlini R, Foresti R. Biological signaling by carbon monoxide and carbon monoxide-releasing molecules. Am J Physiol Cell Physiol. 2017;312:C302-C313.

7. Otterbein LE, Foresti R, Motterlini R. Heme oxygenase-1 and carbon monoxide in the heart: the balancing act between danger signaling and pro-survival. Circ Res. 2016;118:1940-1959.

8. Lakkisto P, Siren JM, Kytö V, Forsten H, Laine M, Pulkki K, Tikkanen I. Heme oxygenase-1 induction protects the heart and modulates cellular and extracellular remodelling after myocardial infarction in rats. Exp Biol Med (Maywood). 2011;236:1437-1448.

9. Ewing JF, Raju VS, Maines MD. Induction of heart heme oxygenase-1 (HSP32) by hyperthermia: possible role in stress-mediated elevation of cyclic 3':5'-guanosine monophosphate.J Pharmacol Exp Ther. 1994;271:408-414.

10. Ling K, Men F, Wang WC, Zhou YQ, Zhang HW, Ye DW. Carbon monoxide and its controlled release: therapeutic application, detection, and development of carbon monoxide releasing molecules (CORMs). J Med Chem. 2018;61:2611-2635.

11. Akamatsu Y, Haga M, Tyagi S, Yamashita K, Graça-Souza AV, Ollinger R, Czismadia E, May GA, Ifedigbo E, Otterbein LE, Bach $\mathrm{FH}$, Soares MP. Heme oxygenase-1-derived carbon monoxide protects hearts from transplant associated ischemia reperfusion injury. FASEB J. 2004;18:771-772.

12. Souders CA, Bowers SL, Baudino TA. Cardiac fibroblast: the renaissance cell. Circ Res. 2009;105:1164-1176.

13. Kohl P. Heterogeneous cell coupling in the heart: an electrophysiological role for fibroblasts. Circ Res. 2003;93:381-383.

14. Villarreal FJ, Kim NN. Regulation of myocardial extracellular matrix components by mechanical and chemical growth factors. Cardiovasc Pathol. 1998;7:145-151.

15. Pellman J, Zhang J, Sheikh F. Myocyte-fibroblast communication in cardiac fibrosis and arrhythmias: mechanisms and model systems. J Mol Cell Cardiol. 2016;94:22-31.

16. Camelliti P, Green CR, LeGrice I, Kohl P. Fibroblast network in rabbit sinoatrial node: structural and functional identification of homogeneous and heterogeneous cell coupling. Circ Res. 2004;94:828835.

17. Cartledge JE, Kane C, Dias P, Tesfom M, Clarke L, Mckee B, Al Ayoubi S, Chester A, Yacoub MH, Camelliti P, Terracciano CM. Functional crosstalk between cardiac fibroblasts and adult cardiomyocytes by soluble mediators. Cardiovasc Res. 2015;105:260-270.

18. Gaudesius G, Miragoli M, Thomas SP, Rohr S. Coupling of cardiac electrical activity over extended distances by fibroblasts of cardiac origin. Circ Res. 2003;93:421-428.

19. Vasquez C, Benamer N, Morley GE. The cardiac fibroblast: functional and electrophysiological considerations in healthy and diseased hearts. J Cardiovasc Pharmacol. 2011;57:380-388.

20. Vasquez C, Mohandas P, Louie KL, Benamer N, Bapat AC, Morley GE. Enhanced fibroblast-myocyte interactions in response to cardiac injury. Circ Res. 2010;107:1011-1020. 
21. Bae H, Lee D, Kim YW, Choi J, Lee HJ, Kim SW, Kim T, Noh YH, Ko JH, Bang H, Lim I. Effects of hydrogen peroxide on voltagedependent $\mathrm{K}^{+}$currents in human cardiac fibroblasts through protein kinase pathways. Korean J Physiol Pharmacol. 2016;20:315-324.

22. Li GR, Sun HY, Chen JB, Zhou Y, Tse HF, Lau CP. Characterization of multiple ion channels in cultured human cardiac fibroblasts. PLoS One. 2009;4:e7307.

23. Wang YJ, Sung RJ, Lin MW, Wu SN. Contribution of $\mathrm{BK}_{\mathrm{Ca}}$-channel activity in human cardiac fibroblasts to electrical coupling of cardiomyocytes-fibroblasts. J Membr Biol. 2006;213:175-185.

24. Mahoney VM, Mezzano V, Morley GE. A review of the literature on cardiac electrical activity between fibroblasts and myocytes. Prog Biophys Mol Biol. 2016;120:128-133.

25. Bae H, Lim I. Effects of nitric oxide on large-conductance $\mathrm{Ca}^{2+}$-activated $\mathrm{K}^{+}$currents in human cardiac fibroblasts through PKA and PKG-related pathways. Clin Exp Pharmacol Physiol. 2017;44:11161124.

26. Chilton L, Ohya S, Freed D, George E, Drobic V, Shibukawa Y, Maccannell KA, Imaizumi Y, Clark RB, Dixon IM, Giles WR. K currents regulate the resting membrane potential, proliferation, and contractile responses in ventricular fibroblasts and myofibroblasts. Am J Physiol Heart Circ Physiol. 2005;288:H2931-H2939.

27. Hu XQ, Zhang L. Function and regulation of large conductance $\mathrm{Ca}^{2+}$-activated $\mathrm{K}^{+}$channel in vascular smooth muscle cells. Drug Discov Today. 2012;17:974-987.

28. Balderas E, Zhang J, Stefani E, Toro L. Mitochondrial $\mathrm{BK}_{\mathrm{Ca}}$ channel. Front Physiol. 2015;6:104.

29. Kim HH, Choi S. Therapeutic aspects of carbon monoxide in cardiovascular disease. Int J Mol Sci. 2018;19:2381.

30. Kapetanaki SM, Burton MJ, Basran J, Uragami C, Moody PCE, Mitcheson JS, Schmid R, Davies NW, Dorlet P, Vos MH, Storey NM, Raven E. A mechanism for CO regulation of ion channels. Nat Commun. 2018;9:907.

31. Wilkinson WJ, Kemp PJ. Carbon monoxide: an emerging regulator of ion channels. J Physiol. 2011;589(Pt 13):3055-3062.

32. Peers C. Modulation of ion channels and transporters by carbon monoxide: causes for concern? Front Physiol. 2012;3:477.

33. Peers C, Boyle JP, Scragg JL, Dallas ML, Al-Owais MM, Hettiarachichi NT, Elies J, Johnson E, Gamper N, Steele DS. Diverse mechanisms underlying the regulation of ion channels by carbon monoxide. Br J Pharmacol. 2015;172:1546-1556.

34. Dong DL, Zhang Y, Lin DH, Chen J, Patschan S, Goligorsky MS, Nasjletti A, Yang BF, Wang WH. Carbon monoxide stimulates the $\mathrm{Ca}^{2+}$-activated big conductance $\mathrm{k}$ channels in cultured human endothelial cells. Hypertension. 2007;50:643-651.

35. Wang R, Wu L, Wang Z. The direct effect of carbon monoxide on $\mathrm{K}_{\mathrm{Ca}}$ channels in vascular smooth muscle cells. Pflugers Arch. 1997;434:285-291.

36. Lim I, Gibbons SJ, Lyford GL, Miller SM, Strege PR, Sarr MG, Chatterjee S, Szurszewski JH, Shah VH, Farrugia G. Carbon monoxide activates human intestinal smooth muscle L-type $\mathrm{Ca}^{2+}$ channels through a nitric oxide-dependent mechanism. Am J Physiol Gastrointest Liver Physiol. 2005;288:G7-G14.

37. Hartsfield CL. Cross talk between carbon monoxide and nitric oxide. Antioxid Redox Signal. 2002;4:301-307.

38. Rotko D, Bednarczyk P, Koprowski P, Kunz WS, Szewczyk A, Kulawiak B. Heme is required for carbon monoxide activation of mito- chondrial $\mathrm{BK}_{\mathrm{Ca}}$ channel. Eur J Pharmacol. 2020;881:173191.

39. Zhou Y, Lingle CJ. Paxilline inhibits BK channels by an almost exclusively closed-channel block mechanism. J Gen Physiol. 2014;144:415-440.

40. Xu W, Liu Y, Wang S, McDonald T, Van Eyk JE, Sidor A, O'Rourke B. Cytoprotective role of $\mathrm{Ca}^{2+}$ - activated $\mathrm{K}^{+}$channels in the cardiac inner mitochondrial membrane. Science. 2002;298:1029-1033.

41. Singh H, Lu R, Bopassa JC, Meredith AL, Stefani E, Toro L. MitoBK $\mathrm{K}_{\mathrm{Ca}}$ is encoded by the Kcnmal gene, and a splicing sequence defines its mitochondrial location. Proc Natl Acad Sci U S A. 2013;110:10836-10841.

42. Dong DL, Bai YL, Cai BZ. Calcium-activated potassium channels: potential target for cardiovascular diseases. Adv Protein Chem Struct Biol. 2016;104:233-261.

43. Decaluwé K, Pauwels B, Verpoest S, Van de Voorde J. Divergent mechanisms involved in CO and CORM-2 induced vasorelaxation. Eur J Pharmacol. 2012;674:370-377.

44. Bihari A, Chung KA, Cepinskas G, Sanders D, Schemitsch E, Lawendy AR. Carbon monoxide-releasing molecule-3 (CORM-3) offers protection in an in vitro model of compartment syndrome. Microcirculation. 2019;26:e12577.

45. Motterlini R. Carbon monoxide-releasing molecules (CO-RMs): vasodilatory, anti-ischaemic and anti-inflammatory activities. Biochem Soc Trans. 2007;35(Pt 5):1142-1146.

46. Portal L, Morin D, Motterlini R, Ghaleh B, Pons S. The COreleasing molecule CORM-3 protects adult cardiomyocytes against hypoxia-reoxygenation by modulating $\mathrm{pH}$ restoration. Eur J Pharmacol. 2019;862:172636.

47. Wilkinson WJ, Kemp PJ. The carbon monoxide donor, CORM-2, is an antagonist of ATP-gated, human P2X4 receptors. Purinergic Signal. 2011;7:57-64.

48. Musameh MD, Fuller BJ, Mann BE, Green CJ, Motterlini R. Positive inotropic effects of carbon monoxide-releasing molecules (CO-RMs) in the isolated perfused rat heart. Br J Pharmacol. 2006;149:11041112 .

49. Al-Owais MM, Hettiarachchi NT, Boyle JP, Scragg JL, Elies J, Dallas ML, Lippiat JD, Steele DS, Peers C. Multiple mechanisms mediating carbon monoxide inhibition of the voltage-gated $\mathrm{K}^{+}$channel Kv1.5. Cell Death Dis. 2017;8:e3163.

50. Polte T, Abate A, Dennery PA, Schröder H. Heme oxygenase-1 is a cGMP-inducible endothelial protein and mediates the cytoprotective action of nitric oxide. Arterioscler Thromb Vasc Biol. 2000;20:1209-1215.

51. Durante W, Kroll MH, Christodoulides N, Peyton KJ, Schafer AI. Nitric oxide induces heme oxygenase-1 gene expression and carbon monoxide production in vascular smooth muscle cells. Circ Res. 1997;80:557-564.

52. Ingi T, Cheng J, Ronnett GV. Carbon monoxide: an endogenous modulator of the nitric oxide-cyclic GMP signaling system. Neuron. 1996;16:835-842.

53. Cao L, Blute TA, Eldred WD. Localization of heme oxygenase-2 and modulation of cGMP levels by carbon monoxide and/or nitric oxide in the retina. Vis Neurosci. 2000;17:319-329.

54. Gustafsson AB, Brunton LL. Attenuation of cAMP accumulation in adult rat cardiac fibroblasts by IL-1beta and NO: role of cGMPstimulated PDE2. Am J Physiol Cell Physiol. 2002;283:C463-471.

55. Núñez L, Vaquero M, Gómez R, Caballero R, Mateos-Cáceres P, 
Macaya C, Iriepa I, Gálvez E, López-Farré A, Tamargo J, Delpón E. Nitric oxide blocks hKv1.5 channels by S-nitrosylation and by a cyclic GMP-dependent mechanism. Cardiovasc Res. 2006;72:80-89.

56. White RE, Kryman JP, El-Mowafy AM, Han G, Carrier GO. cAMPdependent vasodilators cross-activate the cGMP-dependent protein kinase to stimulate $\mathrm{BK}_{\mathrm{Ca}}$ channel activity in coronary artery smooth muscle cells. Circ Res. 2000;86:897-905.

57. Gonzalez DR, Treuer A, Sun QA, Stamler JS, Hare JM. S-Nitrosylation of cardiac ion channels. J Cardiovasc Pharmacol. 2009;54:188195.

58. Lima B, Forrester MT, Hess DT, Stamler JS. S-nitrosylation in cardiovascular signaling. Circ Res. 2010;106:633-646.

59. Martínez-Ruiz A, Lamas S. S-nitrosylation: a potential new paradigm in signal transduction. Cardiovasc Res. 2004;62:43-52.

60. Ahern GP, Hsu SF, Klyachko VA, Jackson MB. Induction of persistent sodium current by exogenous and endogenous nitric oxide. $J$ Biol Chem. 2000;275:28810-28815.

61. Yue ZJ, Xu PT, Jiao B, Chang H, Song Z, Xie MJ, Yu ZB. Nitric oxide protects L-type calcium channel of cardiomyocyte during longterm isoproterenol stimulation in tail-suspended rats. Biomed Res Int. 2015;2015:780814.

62. Sun J, Picht E, Ginsburg KS, Bers DM, Steenbergen C, Murphy E.
Hypercontractile female hearts exhibit increased S-nitrosylation of the L-type $\mathrm{Ca}^{2+}$ channel alpha1 subunit and reduced ischemia/ reperfusion injury. Circ Res. 2006;98:403-411.

63. Bai CX, Namekata I, Kurokawa J, Tanaka H, Shigenobu K, Furukawa T. Role of nitric oxide in $\mathrm{Ca}^{2+}$ sensitivity of the slowly activating delayed rectifier $\mathrm{K}^{+}$current in cardiac myocytes. Circ Res. 2005;96:64-72.

64. Bai CX, Takahashi K, Masumiya H, Sawanobori T, Furukawa T. Nitric oxide-dependent modulation of the delayed rectifier $\mathrm{K}^{+}$current and the L-type $\mathrm{Ca}^{2+}$ current by ginsenoside $\mathrm{Re}$, an ingredient of Panax ginseng, in guinea-pig cardiomyocytes. Br J Pharmacol. 2004;142:567-575.

65. Gómez R, Núñez L, Vaquero M, Amorós I, Barana A, de Prada T, Macaya C, Maroto L, Rodríguez E, Caballero R, López-Farré A, Tamargo J, Delpón E. Nitric oxide inhibits Kv4.3 and human cardiac transient outward potassium current (Ito1). Cardiovasc Res. 2008;80:375-384.

66. Lai MH, Wu Y, Gao Z, Anderson ME, Dalziel JE, Meredith AL. BK channels regulate sinoatrial node firing rate and cardiac pacing in vivo. Am J Physiol Heart Circ Physiol. 2014;307:H1327-H1338.

67. Kohl P, Gourdie RG. Fibroblast-myocyte electrotonic coupling: does it occur in native cardiac tissue? J Mol Cell Cardiol. 2014;70:37-46. 